\title{
The Institute for Soil Fertility Research 1890-1990
}

\author{
K. HARMSEN
}

Institute for Soil Fertility Research, P.O. Box 30003, NL 9750 RA Haren, Netherlands

\begin{abstract}
The Institute for Soil Fertility Research in Haren, the Netherlands, was established as a State Agricultural Experimental Station in Groningen on 2 January 1890. From 1890-1915 the major occupation of the experimental station was the quality control of animal feedstuffs and fertilizer materials for agriculture in the northern part of the Netherlands. In 1916, the experimental station was given the task to conduct scientific research on arable and grassland farming in the Netherlands. The research areas after 1916 can be distinguished into (1) soils and hydrology, (2) soil fertility and fertilizers, and (3) crops and crop production. Of these research areas, only soil fertility and fertilizers is still within the domain of the present Institute for Soil Fertility Research. The other research areas have been transferred to existing (soils) or newly founded institutions (hydrology, crops, crop production). The research on the 'fertility factors' laid the foundation for the system of fertilizer recommendations in the Netherlands, on the basis of soil analysis. In recent years, research emphasis has shifted to environmental issues and the ecology of agricultural systems, making use of simulation modelling and other mathematical tools for the description of soil-crop ecosystems.
\end{abstract}

\section{Introduction}

The roots of the Institute for Soil Fertility Research in Haren, the Netherlands, go back to the State Agricultural Experimental Station in Groningen, the Netherlands, which was officially opened on 2 January 1890 . The editorial board of the Netherlands Journal of Agricultural Science (NJAS) has kindly agreed to devote a special issue to soil fertility research, to mark the centennial of the institute.

The present paper gives a brief overview of the history of the Institute for Soil Fertility Research, thus placing the scientific research reported in this issue of NJAS in a historical context. The information on which the present paper is based, was derived from a book entitled 'Institute for Soil Fertility Research 1890-1990' (Harmsen, 1990). As most of the original references are not readily available to readers outside the Netherlands, no further references will be given in the present paper. The interested readers in the Netherlands are referred to Harmsen (1990).

\section{The system of State Agricultural Experimental Stations in the Netherlands}

The origin of the Agricultural Experimental Stations in Western Europe goes back to the mid-nineteenth century, when experimental stations were established in England (Rothamsted, 1840), Germany (1850), France (1868), and Belgium (1872). In the Netherlands, the efforts of Adolf Mayer (1843-1942), at the time teacher in 


\section{K. HARMSEN}

agricultural chemistry at the State Agricultural College in Wageningen, resulted in the establishment of the first Agricultural Experimental Station in Wageningen, on 1 February 1877. It was established to meet the demand for research on fertilizers, animal feedstuffs and seeds, to inform the farmers on the use of these materials, and to assist the farmers whenever they needed scientific advice. In practice, there was mainly a need for quality control of fertilizers, animal feedstuffs and seeds, and soon the chemical (and botanical) analysis of these materials became the major occupation of the experimental station.

It took several years before the government and the farmers' organizations were convinced of the need to establish a network of state experimental stations in the Netherlands. Adolf Mayer mentions in this connection that the farmers in the Netherlands were relatively prosperous in those days, that the distribution of the landownership was quite reasonable, and that the overseas colonies offered employment and opportunities to those who could not find suitable employment at home. Hence, the need to invest in agricultural research and quality control did not appear to be very urgent. Also, the liberal principles, which prevailed from the middle of the 19th century onwards, did not encourage state interference with what were considered private agricultural affairs.

However, in the late eighteen-seventies, the supply of large quantities of lowpriced agricultural products from the United States of America on the European markets led to a steep decline in the prices of these commodities, which affected the Dutch farmers in particular, as they were strongly dependent on the export of their products. The resulting agricultural crisis exposed a serious weakness of Dutch agriculture at that time: during the past decades, there had been insufficient attention to scientific developments and innovative technologies in agriculture. As a result, Dutch agriculture had lost its leading position in Western Europe. Concern about the competitiveness of Dutch agriculture resulted in the establishment, in 1886, of a State Commission on Agriculture, headed by C. J. Sickesz. One of the recommendations of this commission was to establish experimental stations in the major agricultural regions of the Netherlands. This led to the establishment of State Agricultural Experimental Stations in Groningen, Hoorn and Breda in 1890. The experimental station in Breda moved to Goes in 1893, and a fifth experimental station was established in Maastricht in 1898. The department of quality control of seeds of the experimental station in Wageningen developed into an independent Agricultural Experimental Station for Seed Quality in 1899. Hence, by the turn of the century there were six experimental stations in the Netherlands: in Wageningen (2), Groningen, Hoorn, Goes and Maastricht.

Five of the six State Agricultural Experimental Stations were each responsible for a certain region of the Netherlands (Fig. 1), whereas the Agricultural Experimental Station for Seed Quality in Wageningen worked for the entire country. The experimental stations were responsible for agricultural research and for the quality control of fertilizers, animal feedstuffs and other materials, in their respective regions. Because of the growing demand for quality control, the experimental stations were unable to spend sufficient time on agricultural research. This unsatisfactory situation led to the reorganization of 1913-1915, when the experimental stations 


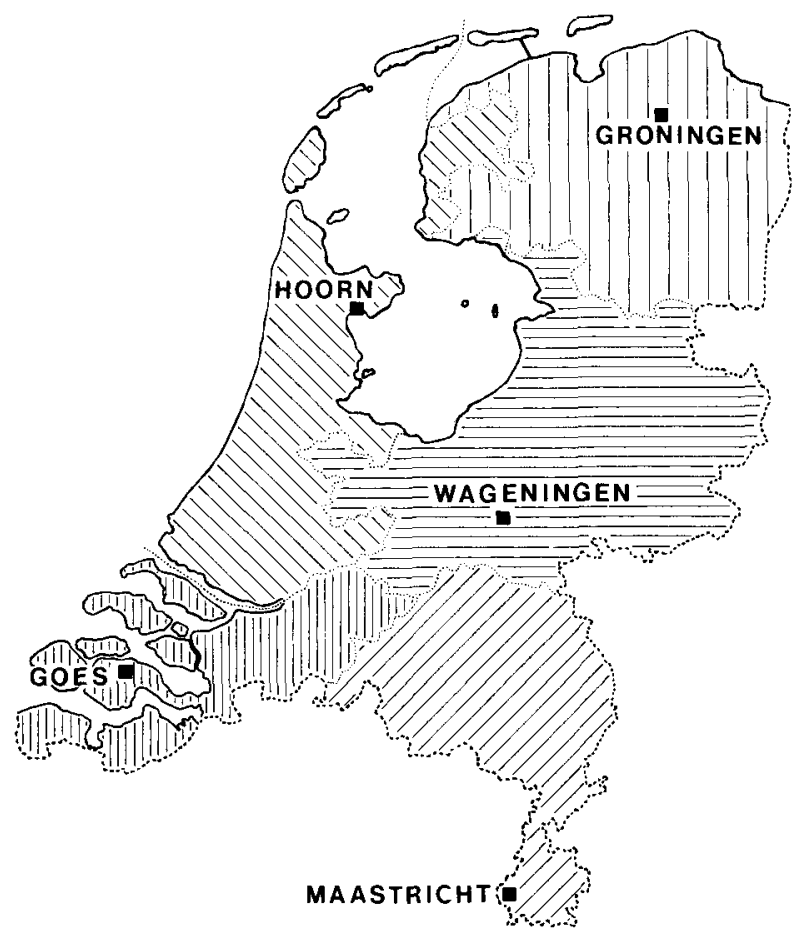

Fig. 1. Regions served by the five State Agricultural Experimental Stations around 1900.

were divided into stations for agricultural research (Groningen and Hoorn) and stations for quality control of fertilizers (Maastricht), animal feedstuffs (Wageningen), seed quality (Wageningen, as from 1899) and other materials, such as herbicides and fungicides (Goes). The experimental station in Groningen became responsible for agricultural research on arable crops and pastures, and the station at Hoorn for research on dairy products and animal feeding. For the history of the latter experimental station, see: Honing \& Langelaar (1990).

As all experimental stations now had country-wide responsibilities, the rationale for the excentric location of most of these stations had ceased to exist. In the years following the reorganization of 1913-1915, most of the experimental stations moved to the center of the country (Wageningen or Lelystad) or were closed down. The State Agricultural Experimental Station in Goes (Fig. 2) was closed down in 1922, the experimental station in Hoorn moved to Lelystad in the mid-seventies and is now called Institute for Livestock Feeding and Nutrition Research (IVVO), whereas the experimental station in Maastricht moved to Wageningen in 1979 and merged to form a new institute in 1980, the State Institute for Quality Control of Agricultural Products (RIKILT). The experimental station in Groningen, however, remained in the north of the Netherlands and developed into the present Institute for Soil Fertility Research in Haren. 


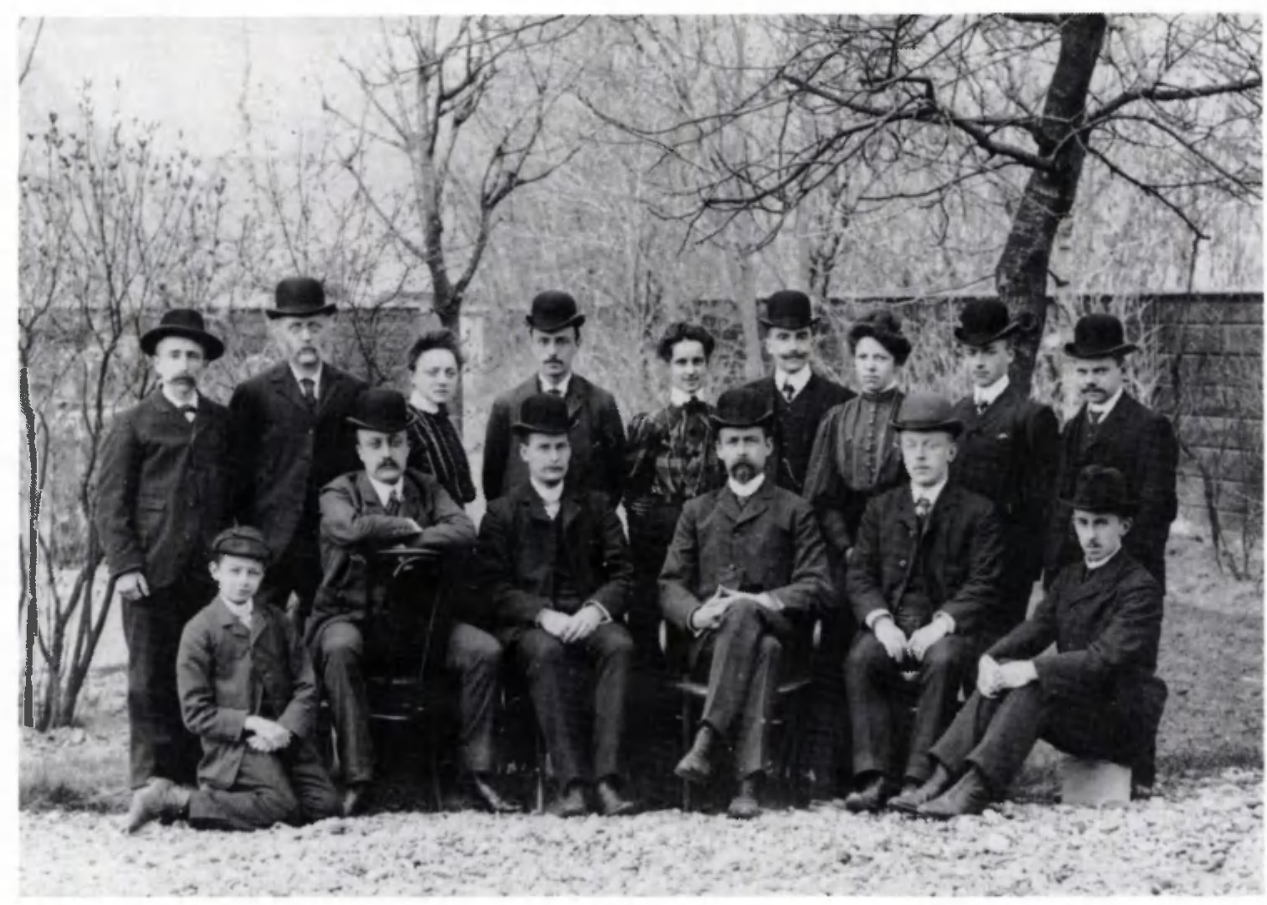

Fig. 2. In the early days of the experimental stations, staff members moved frequently from one station to the other. For example, four future directors at the experimental station in Groningen had previously worked at the station in Goes: Dr A. van Bijlert (1891-1893), Dr B. Sjollema (1893), Dr D. J. Hissink (1902-1906) and Ir J. G. Maschhaupt (1902-1907). The photograph shows the personnel of the experimental station in Goes, at the occasion of the departure of Dr D. J. Hissink as director of the station in 1906. In 1907, Dr D. J. Hissink was succeeded by Dr J. C. de Ruyter de Wildt, who had worked as a research chemist at the station in Groningen from 1904-1907. Photograph: front row, third from the left: Ir J. G. Maschhaupt; next to him: Dr D. J. Hissink.

Note: In the Dutch academic system, the title of 'Drs' (Doctorandus) refers to a person who has obtained a university degree, whereas the title 'Ir' (Engineer) refers to a degree obtained at a technical university. Both degrees are comparable to a M.Sc. degree. The titles 'Dr' and 'Prof.' have the same meaning as in the UK and USA systems.

\section{State Agricultural Experimental Station in Groningen (1890-1916)}

The State Agricultural Experimental Station in Groningen was officially opened on 2 January 1890. The experimental station was accomodated in rented houses, at Nieuwe Ebbingestraat 26 (1889-1891) and Westersingel 5 (1891-1904), before it was moved to a new (own) building, at Prof. H. C. van Hallstraat 3 in Groningen, which was officially opened on 13 February 1904. This building was used by the experimental station until 1968, when new facilities in Haren became available.

The first director of the experimental station was Dr A. F. Holleman, who assumed his duties on 1 August 1889. Under the directorships of Dr A. F. Holleman 


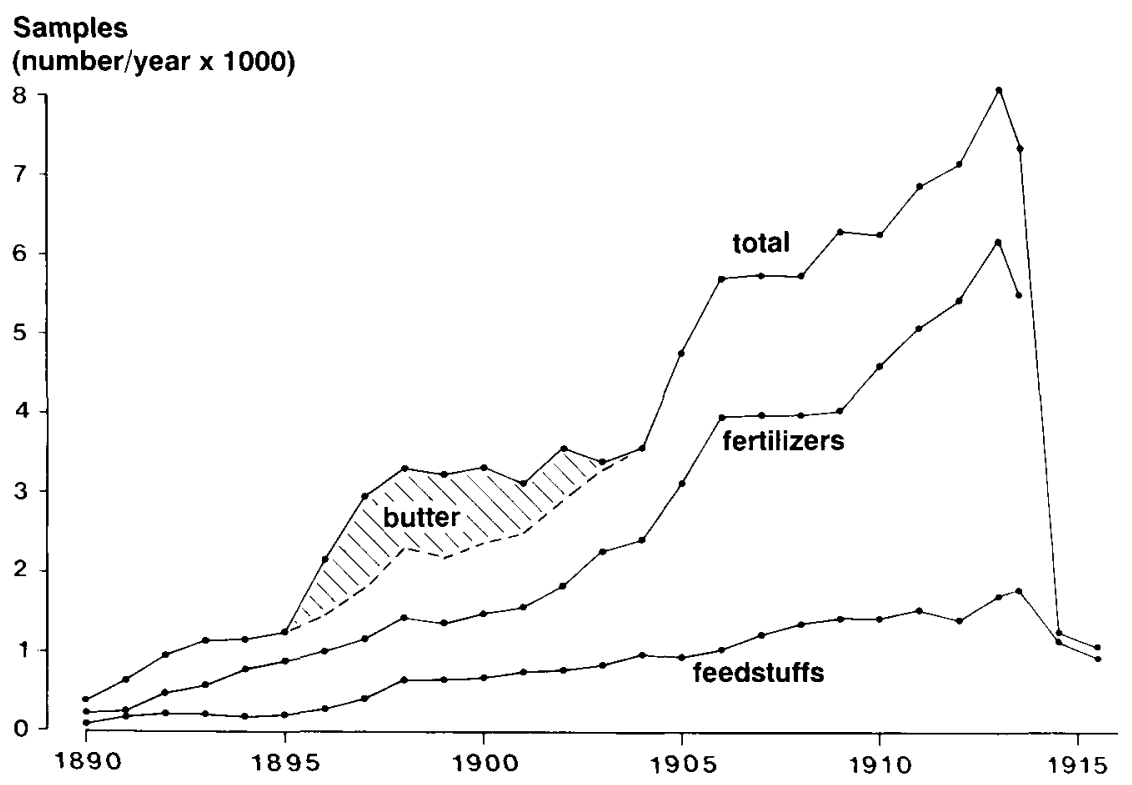

Fig. 3. Numbers of samples of animal feedstuffs, fertilizers and butter, and the total number of samples that were analysed annually by the State Agricultural Experimental Station in Groningen during 1890-1915.

(1889-1893), Dr A. van Bijlert (1894-1895), Dr B. Sjollema (1895-1907) and Ir J. G. Maschhaupt (1907-1916), the core staff of the experimental station increased from 3 in 1890 to 27 by the end of 1916 .

The major occupation of the State Agricultural Experimental Station consisted of the chemical analysis of fertilizer materials, animal feedstuffs and butter samples. The total number of samples that were analysed increased from 21 during the last two months of 1889 to about 8000 in 1913 (Figs. 3-4). From 1903-1904 onwards, the analysis of butter samples was taken over by the newly established State Dairy Station at Leiden. As part of a reorganization of the State Agricultural Experimental Stations in the Netherlands, the analysis of fertilizer samples was taken over by the experimental station in Maastricht as from 1 May 1914, and the analysis of animal feedstuffs by the experimental station in Wageningen as from 1 May 1916.

The experimental stations had a dual task: quality control and scientific research. Because of the large (and ever increasing) numbers of samples to be analysed, and the limited resources of the experimental stations, the scientific research program did not develop as well as had been hoped for when the experimental stations were established. However, some scientific research was conducted by the experimental stations.

The emphasis in the research program in Groningen was on soils, soil fertility, and fertilizers. One of the most important lines of research was the research on the so-called 'soil diseases', that is, micronutrient-deficiencies induced by low (magnesi- 


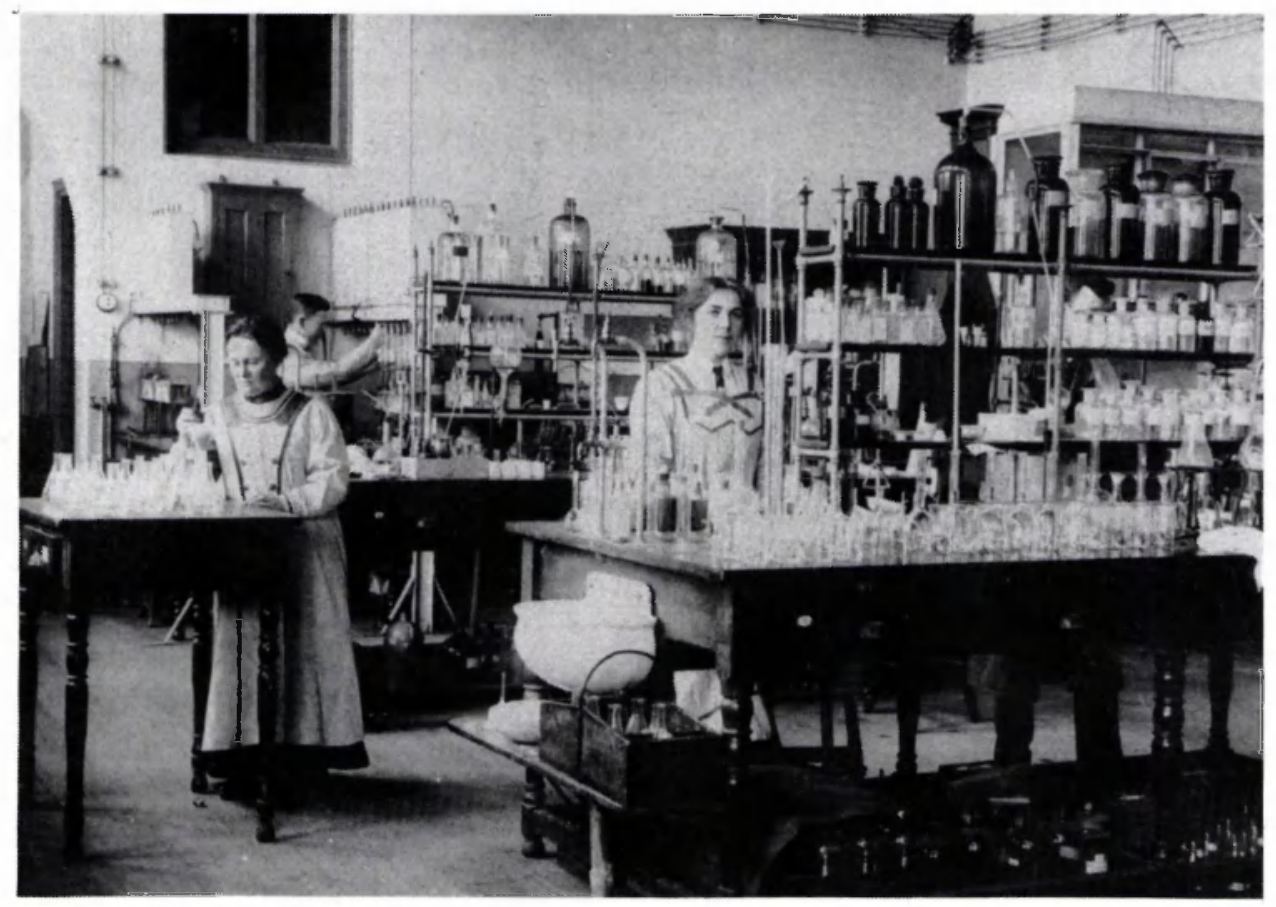

Fig. 4. Inside the analytical laboratory of the experimental station.

um) or high (manganese) $\mathrm{pH}$. This research was started around 1908 by Dr B. Sjollema and Ir J. Hudig, and was continued by the latter, together with $\mathbf{C}$. Meijer.

Although the emphasis in Groningen was on soils, soil fertility and fertilizers, the area covered by the research program of the experimental station was very broad in those days and included the quality and cultivation of arable crops and grassland (including rooting studies), plant nutrition, rainwater quality, hydrology, soils and soil fertility, and fertilizers, including animal manures.

\section{State Agricultural Experimental Station for Arable and Grassland Farming (1916-1939)}

Following the reorganization of 1913-1915, the experimental station in Groningen was renamed State Agricultural Experimental Station for Arable and Grassland Farming (Fig. 5). Its task was to conduct research and experiments on arable and grassland farming. The emphasis was on three lines of research: (1) soils and hydrology, (2) soil fertility and fertilizers, and (3) production and quality of crops.

As from 1 May 1916, the experimental station was divided into five independent research departments, each of them headed by a 'director'. Together the directors of the research departments formed the 'Board of Directors' and appointed each year a chairman and a secretary from their midst. The research departments and 


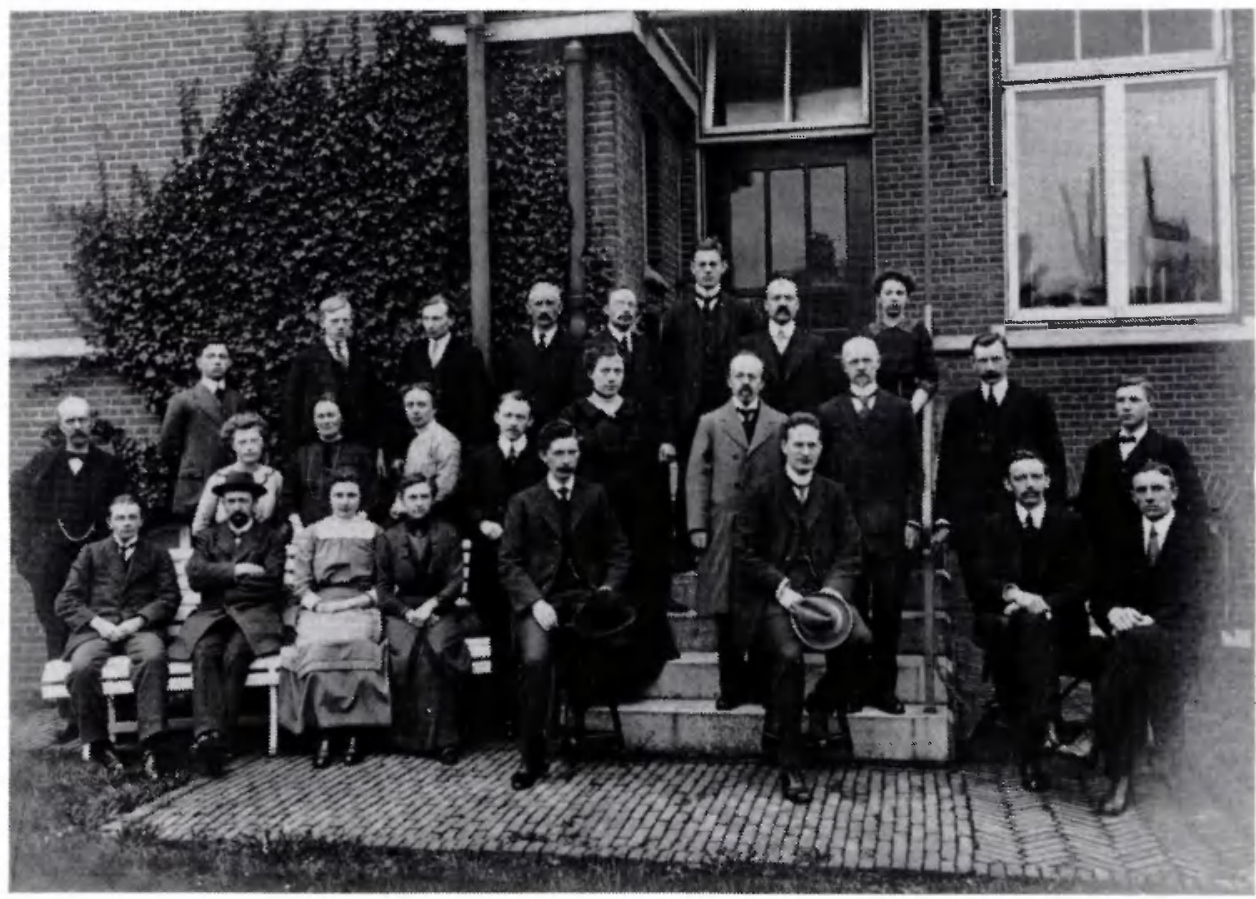

Fig. 5. The staff of the experimental station in 1916. Front row, sixth from the left: Ir. J. G. Maschhaupt; behind him, to the left: Ir. J. Hudig.

their directors were:

1. Department for crop production on clay and sandy clay soils - Ir J. G. Maschhaupt (1916-1930).

2. Department for crop production on sandy and peat soils - Ir J. Hudig (1916-1930).

3. Department for general soil research - Dr D. J. Hissink (1916-1926).

4. Department for bacteriological research - Dr N. L. Söhngen (1916-1918), Dr

F. C. Gerretsen (1919-1930).

5. Department for botanical research - Dr K. Zijlstra (1916-1930).

After this reorganization, the 1 st and 2nd departments remained in the main building of the experimental station, at Prof. H. C. van Hallstraat 3 (Figs. 6-7). The 3rd department, later the Institute of Soil Science, was accomodated in a rented house at Herman Colleniusstraat 25, from 1930-1931 supplemented by a house at Jozef Israëlsstraat 42. In July 1931 the Institute of Soil Science moved to a new (own) building, at Verlengde Oosterweg 122 in Groningen (Fig. 8). This building was used until 1968, when new facilities in Haren became available. The 4th department was accomodated in a rented house at Wassenberghstraat 19 , whereas for the 5th department initially no facilities were available, forcing Dr K. Zijlstra to use some space in his own house for his botanical work. When Dr N. L. Söhngen left for Wageningen in 1918, Dr K. Zijlstra moved to the Wassenberghstraat, with the 


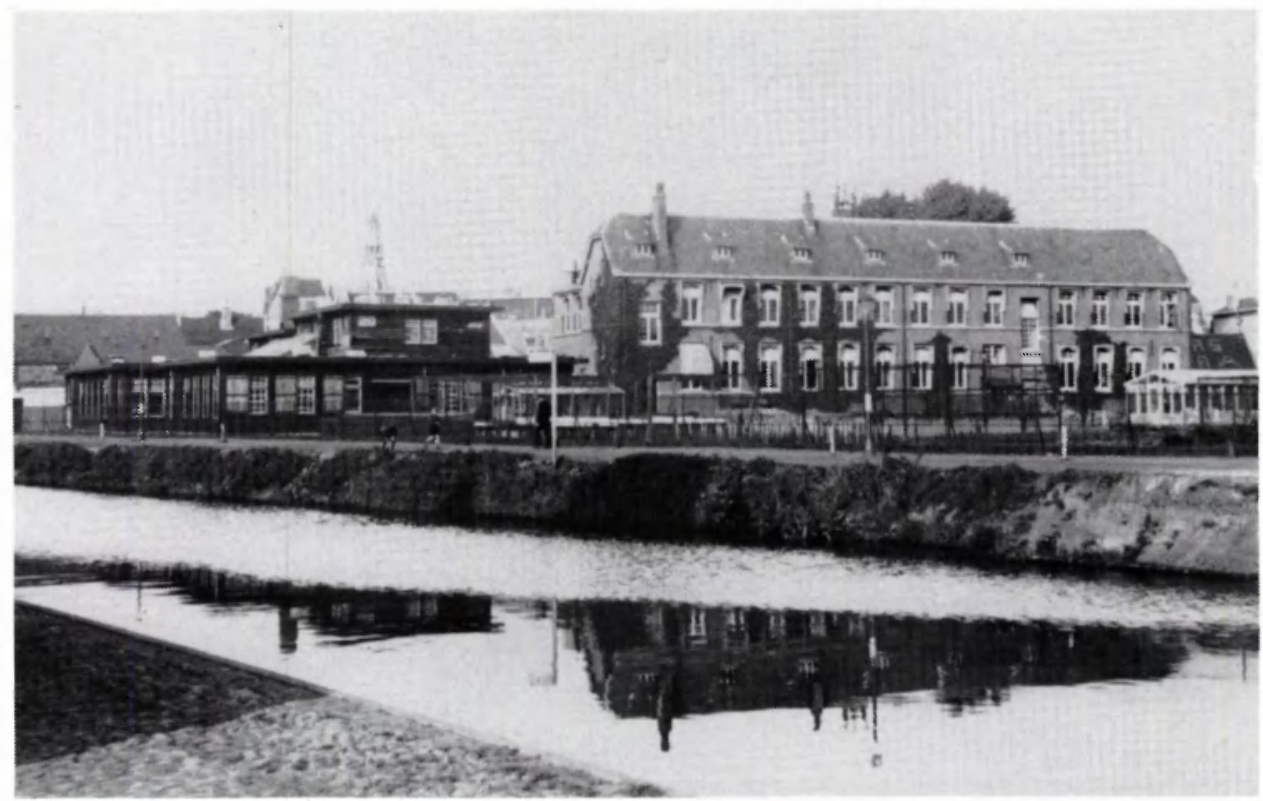

Fig. 6. The main building of the experimental station at Prof. H. C. van Hallstraat 3 in Groningen. Wooden building to the left: Laboratory for Soil Testing.

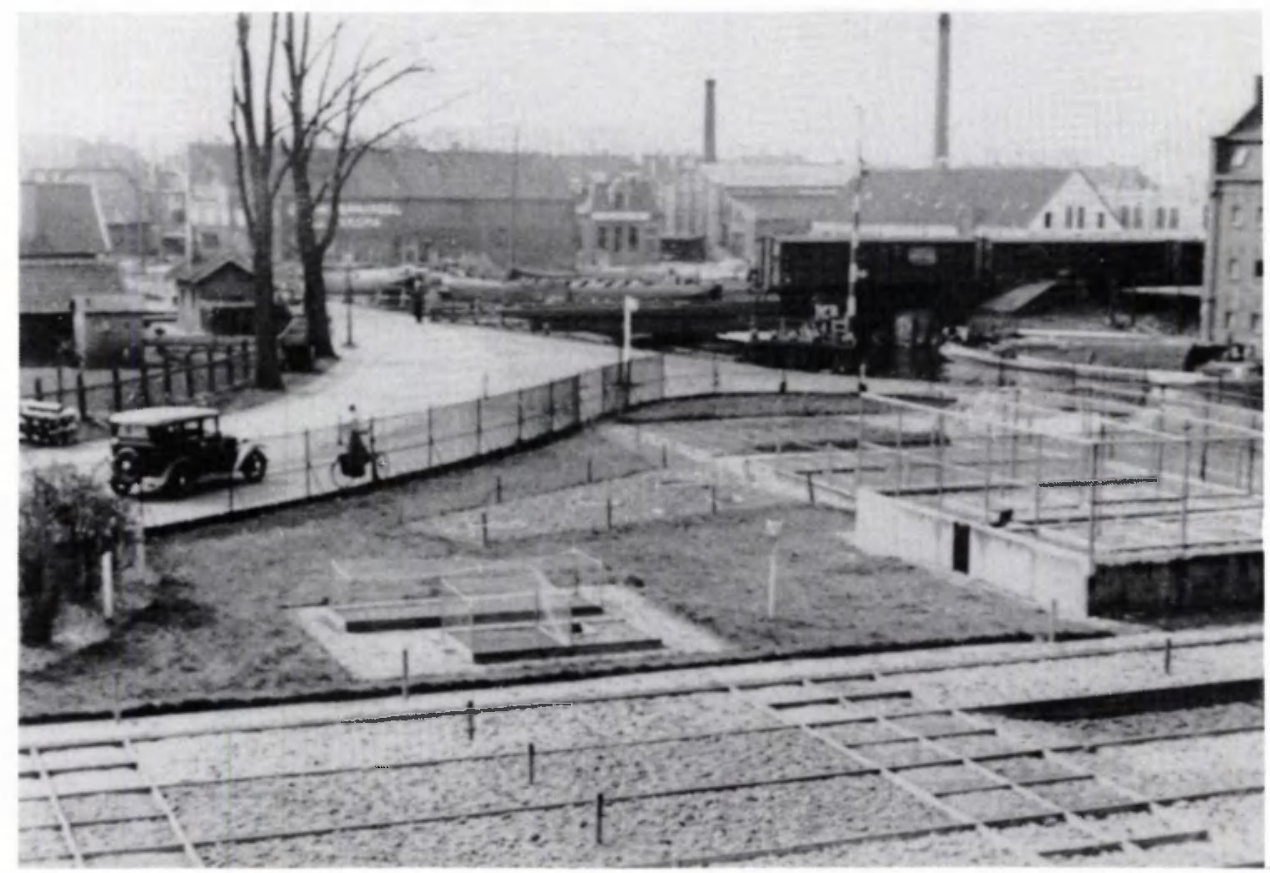

Fig. 7. The experimental grounds adjacent to the main building. Front, to the right: lysimeters. 


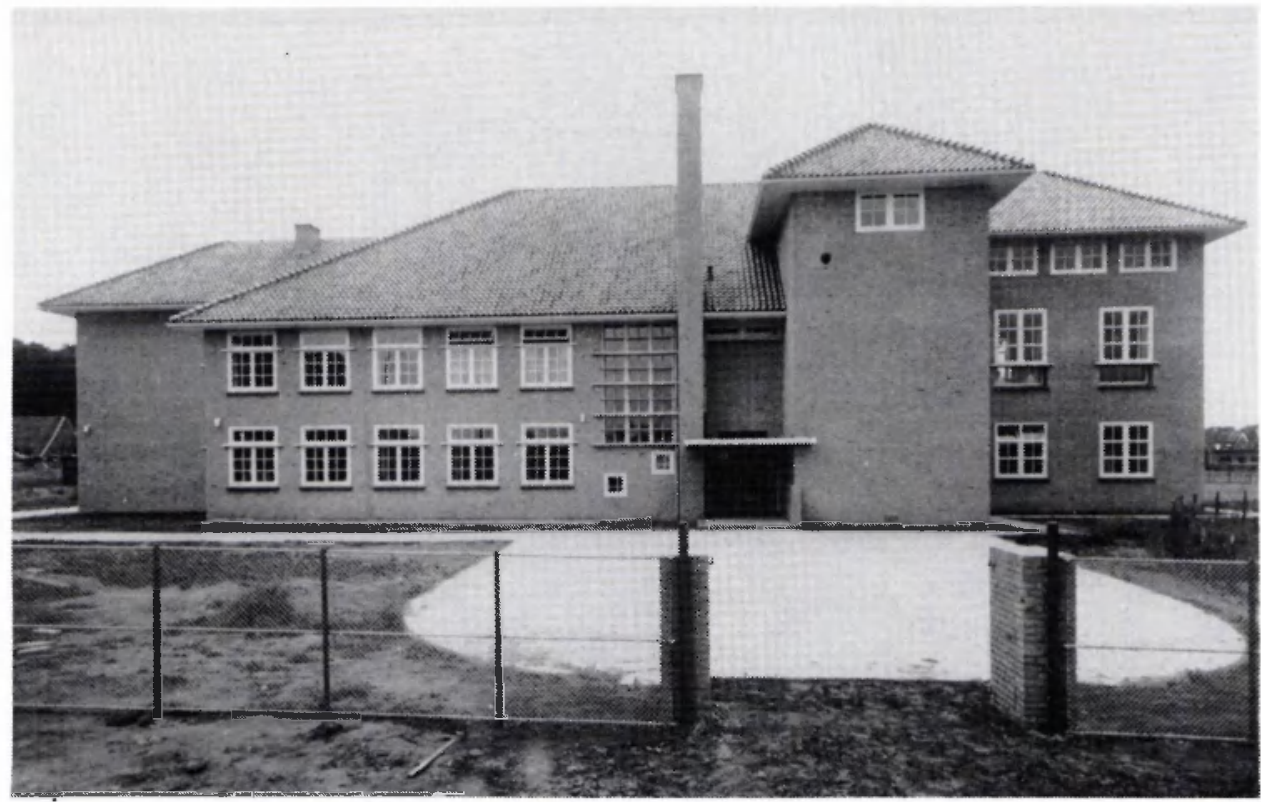

Fig. 8. The building of the Institute of Soil Science at Verlengde Oosterweg 122 in Groningen.

result that no space was available for Dr F. C. Gerretsen when he arrived in Groningen in 1919. This unsatisfactory situation came to an end when both departments moved to a large (rented) house at Eemskanaal ZZ 1, a building that was used until 1968 (Fig. 9).

The 3rd department for general soil research became an independent institute in 1926, the Institute of Soil Science in Groningen, which remained independent until 1939, when Dr D. J. Hissink retired as director of the institute. Soil research developed strongly under the directorship of Dr D. J. Hissink. The main emphasis was on physicochemical soil research, but under the leadership of Dr S. B. Hooghoudt hydrological research also gained importance. Much research was done on the soils reclaimed from the 'Zuiderzee'. The physicochemical and hydrological knowledge about these soils helped to prepare the 'polders' for cultivation.

The four research departments (other than the soils department) of the experimental station remained autonomous until October 1930, when they were united under one 'general' director, Prof. Dr O. de Vries. After the departure of Ir J. Hudig to Wageningen in 1931, the 1st and 2nd departments were reorganized and two new departments were formed: a chemical department, headed by Ir J. G. Maschhaupt, and an agronomic department, headed by Ir P. G. Meijers.

The most important line of research, in terms of impact on agriculture in the Netherlands, was probably the research on soil fertility and fertilizers, commonly referred to as the research on the 'fertility factors'. The notion of 'fertility factor' refers to a quantifiable soil property that may affect soil productivity (i.e. crop yields). Examples of fertility factors are the lime and potash status of soils, but also 


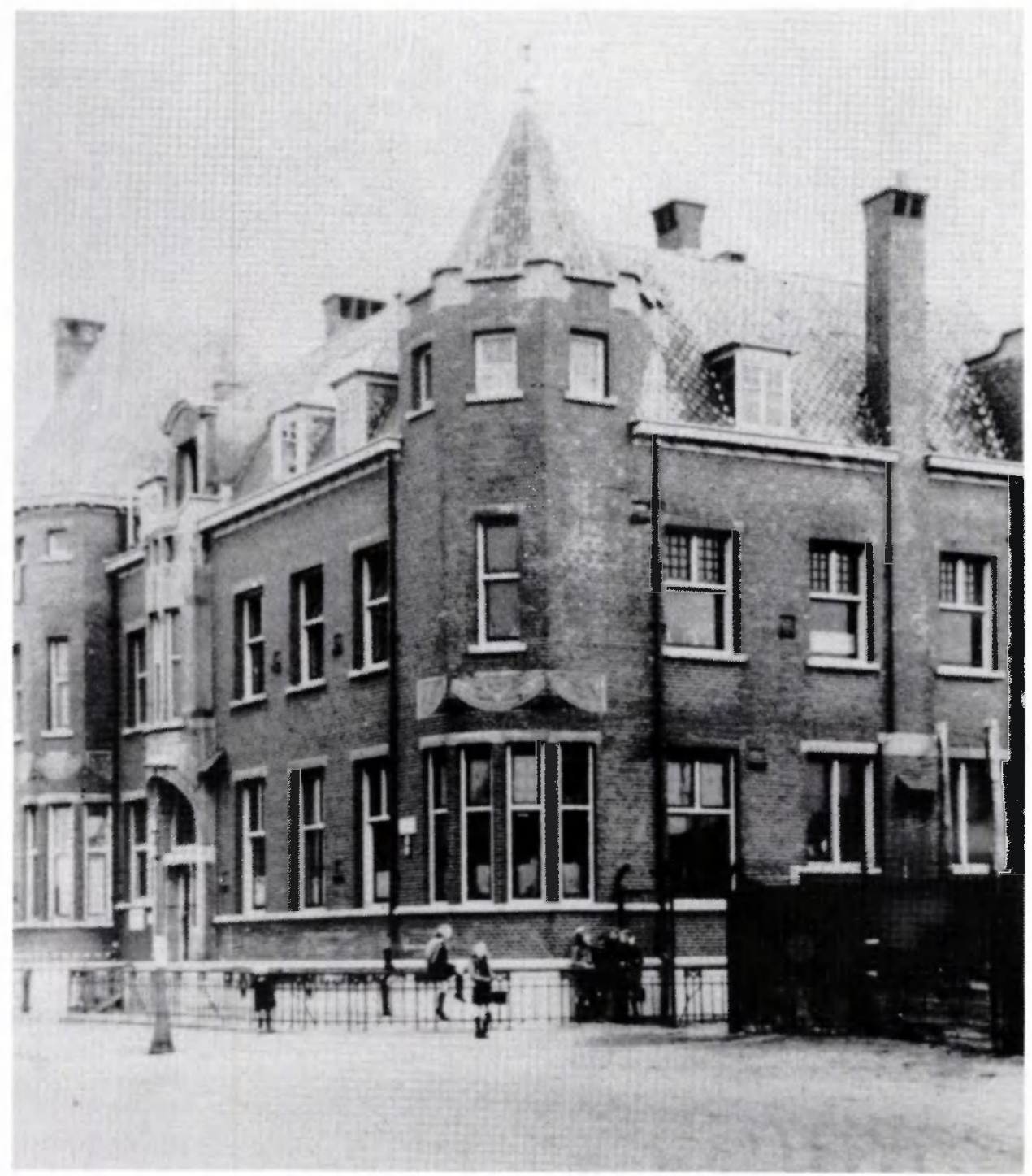

Fig. 9. The building at Eemskanaal $\mathrm{ZZ} 1$ in Groningen, where the 4th and 5th departments of the experimental station were housed.

the cation-exchange capacity, moisture-storage capacity, micronutrient availability, etc.

Although soil fertility research can be traced back to Dr A. F. Holleman and Dr B. Sjollema, the breakthrough came in the mid-twenties, when it was shown that the occurrence of the so-called 'soil diseases' depended on the lime status of the soil. The lime status of a soil was expressed as the lime index, which is a measure of the 

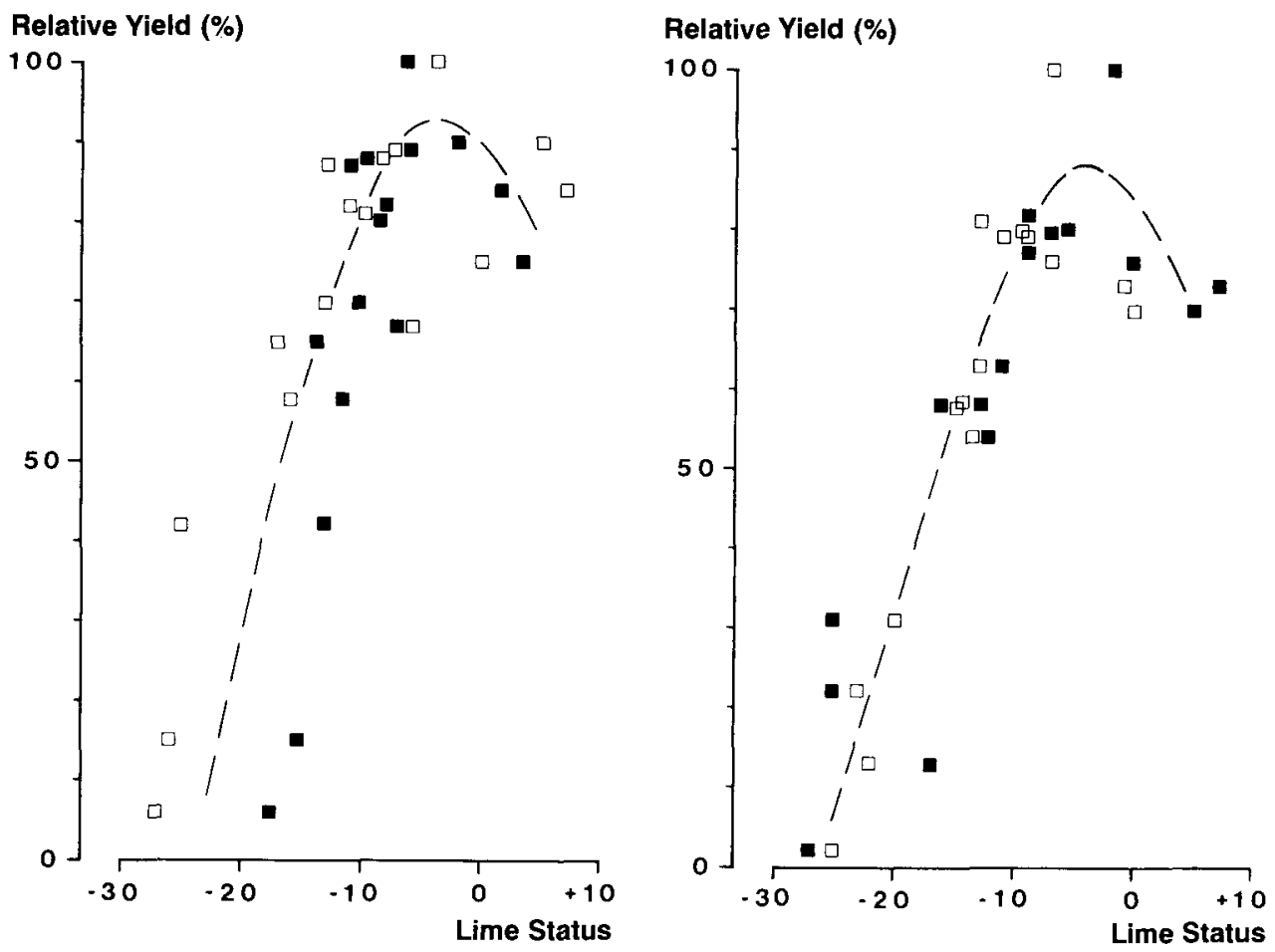

Fig. 10. Relative yields of sugar beet in 1924 (left) and green peas in 1925 (right) as a function of the lime status of the soil at the experimental field at Spitsbergen, Netherlands. The lime status is indicated by an index, which ranged from about -30 (pH about 4.1$)$ to $+10(\mathrm{pH}$ about 7.3) under the conditions of the experiment. Open symbols $(\square)$ refer to the lime status at the start of the season, closed symbols (ם) to the lime status after harvest.

amount of lime needed to reach a pH of 6.5. In experiments with sugar beet (1924) and green peas (1925) at Spitsbergen, the Netherlands, Ir J. Hudig and C. Meijer showed that crop yields increased with increasing lime index up to a maximum (or: optimum) yield at lime-index values between $-10(\mathrm{pH}$ about 5.7) and $0(\mathrm{pH}$ about 6.5), and thereafter decreased with increasing lime index (Fig. 10). The low yields at low lime index were later shown to be caused by magnesium deficiency at low $\mathrm{pH}$, whereas the low yields at high lime index were shown to be due to manganese deficiency at high $\mathrm{pH}$.

The research was not limited to the lime status of soils, but included other fertility factors, such as the potash status and the phosphate status, as well. In many cases 'optimum curves', similar to the ones shown in Figure 10, were obtained when relative yields were plotted as a function of a particular fertility factor. This led to the concept in which yield was considered to be a function of a number of (interacting) 
fertility factors. The methodology of the research on the fertility factors was largely developed under the directorship of Prof. Dr O. de Vries. The scientists involved in this research included Drs P. Bruin, Dr Ir H. J. Frankena, Dr F. van der Paauw and Ir W. C. Visser.

The research on the lime status derived its practical significance from the fact that the 'soil diseases' were widespread in those days and that it was now shown that farmers could overcome these 'soil diseases' by either liming their soils, at low $\mathrm{pH}$, or applying an acidifying fertilizer, such as ammonium sulfate, at high $\mathrm{pH}$. As a result of these findings, the demand for soil analysis by farmers increased strongly in the early twenties. As the experimental station was not equipped for such large numbers of routine analyses, the director of the 2 nd department, Ir J. Hudig, took the initiative to establish a laboratory for soil testing on a commercial basis. This resulted in the foundation, in 1927, of the Laboratory for Soil Testing (BLG) in Groningen. The director of the 2nd department became also director of the laboratory, until 1930, when the general director, Prof. Dr O. de Vries, formally took over this responsibility. In practice, however, it was Ir F. J. A. Dechering who was in charge of the operations of the laboratory. The Laboratory for Soil Testing was housed in a building on the grounds of the experimental station at Prof. H.C. van Hallstraat in Groningen (Fig. 6). After 1945 the head office of the laboratory moved to Oosterbeek, and in 1965 the establishment in Groningen closed down.

The research on the fertility factors laid the foundation for the fertilizer recommendations in the Netherlands, on the basis of soil analysis. In its present form, this system of fertilizer recommendations considers such factors as soil nutrient status (soil analysis), soil type, type of crop, cropping history, crop residue management and the use of animal or green manures. Although in recent years the use of fertilizers in agriculture has been in discussion, the existing system of fertilizer recommendations is still one of the more advanced systems in Europe and has contributed significantly to the rise of agriculture in the Netherlands after the second world war.

\section{Agricultural Experimental Station and Institute of Soil Science (1939-1957)}

In 1939, a reorganization took place, which led to the separation of soil and soil fertility research on the one hand, and crop and crop production research on the other. In the course of 1939 the Central Institute for Agricultural Research (CILO) was established in Wageningen and this institute took over the tasks (as well as the staff) of the experimental station in Groningen in the field of crop and crop production research. In 1956, the CILO terminated its activities and its staff was divided over three newly founded institutions in Wageningen: the Institute for Biological and Chemical Research on Field Crops and Herbage (IBS), the Experimental Station for Arable and Grassland Farming (PAW) and the Institute for Research on Storage and Processing of Agricultural Products (IBVL). In 1970, the PAW was moved to Lelystad and split up into two new stations: the Experimental Station for Cattle, Sheep and Horse Husbandry (PR) and the Experimental Station for Arable Farming (PA). The IBS merged to form the Center for Agrobiological Research (CABO) in Wageningen (1975), the PA merged to form the Experimental Station for Arable 
Farming and Field Production of Vegetables (PAGV) in Lelystad (in 1976), and the IBVL merged to form the Institute for Agrotechnological Research (ATO) in Wageningen (1989). Hence, the research on the production, storage and quality of crops, conducted by the experimental station in Groningen until 1939, is at present divided over the research programs of four institutions: CABO and ATO in Wageningen, and PR and PAGV in Lelystad.

The Institute of Soil Science, which had been independent since 1926, was reunited with the experimental station in 1939 and the new institution was renamed 'Agricultural Experimental Station and Institute of Soil Science'. In 1945 this institution became part of the Netherlands Organization for Applied Scientific Research (TNO) and the name was changed into 'Agricultural Experimental Station and Institute of Soil Science TNO'.

In 1939 , a cooperative agreement was concluded between the experimental station in Groningen and the Directorate of State Mines (DSM) in Limburg. This agreement arranged for the appointment of Dr Ir E. G. Mulder at the experimental station in Groningen. His task was to investigate the role of nitrogen in arable and grassland farming. The cooperation between the experimental station and the DSM went back to the early thirties, when C. Boudewijn, director of the Agricultural Bureau of the State Mines, took the initiative to establish a number of experimental fields to test nitrogen fertilizers throughout the country. After World War II, the cooperation between the fertilizer industry, by then organized in the Netherlands Fertilizer Institute (NMI), and the experimental station was continued and, in fact, strengthened. In 1956, Dr Ir E. G. Mulder became professor of microbiology at the Wageningen Agricultural University and he was succeeded at the experimental station in Groningen by Dr Ir P. F. J. van Burg. In 1964, a second scientist, Dr Ir K. Dilz, was placed by the fertilizer industry at the experimental station. In 1974, Dr Ir P. F. J. van Burg became director of the NMI. He was succeeded at the experimental station by Dr Ir W. H. Prins. At present, the scientific staff of the NMI-establishment in Haren consists of Dr O. Oenema (head) and Ir P. J. van Erp.

The research departments that had been autonomous during 1916-1930 and united under one general director during 1930-1939, disappeared gradually during the period 1939-1957 and were replaced by a project-oriented research organization. In 1945, Prof. Dr O. de Vries left the institute and was succeeded by Drs P. Bruin as acting general director. The Laboratory for Soil Testing became independent and Ir F. J. A. Dechering became its director.

As for soil fertility and fertilizer research, the period 1939-1957 may be considered a period of extension and intensification of the research into the fertility factors. Areas on which research was focussed, or new areas of research, included the role of micronutrients, organic matter turnover in soils, the nitrogen cycle in agricultural systems, and soil physical properties and soil structure.

\section{Institute for Soil Fertility Research (1957-1990)}

In 1956 the Institute for Land and Water Management Research (ICW) was established in Wageningen and the hydrological research of the experimental station in 
Groningen was transferred (including the staff) to the newly founded institute in Wageningen. The Agricultural Experimental Station and Institute of Soil Science TNO became a foundation of the Ministry of Agriculture and Fisheries in 1957, and the name of the institution was changed into Institute for Soil Fertility Research. In 1958 the fertilization research for horticulture was transferred to the Institute for Soil Fertility Research.

In 1967, Drs P. Bruin retired as director of the Institute for Soil Fertility Research. In the same year he received a honorary doctor's degree from the JustusLiebig University in Giessen, West-Germany. He was succeeded by Ir C. M. J. Sluijsmans, who remained director until 1985, when he stepped down as director, for health reasons. Ir C. M. J. Sluijsmans remained at the institute as a research scientist in the department of fertilization and plant nutrition, until his early retirement in 1987. He was succeeded by Dr P. J. Lont as acting director of the institute, until the new director, Dr Ir K. Harmsen, assumed his duties in 1986.

After 12 years of preparation, the new facilities of the institute were finally ready in 1968, thus putting an end to an almost continuous state of housing problems, which had started in 1916, with the foundation of the five research departments of the experimental station. In 1968 the institute moved from its three locations, that is, Prof. H. C. van Hallstraat 3, Eemskanaal ZZ 1 and Verlengde Oosterweg 122, to the new facilities at Oosterweg 92 in Haren (Fig. 11).

The period after 1957 may be considered a period of consolidation of the research into the fertility factors. There were also new lines of research, however, in particular in the field of environmental quality and soil ecology.

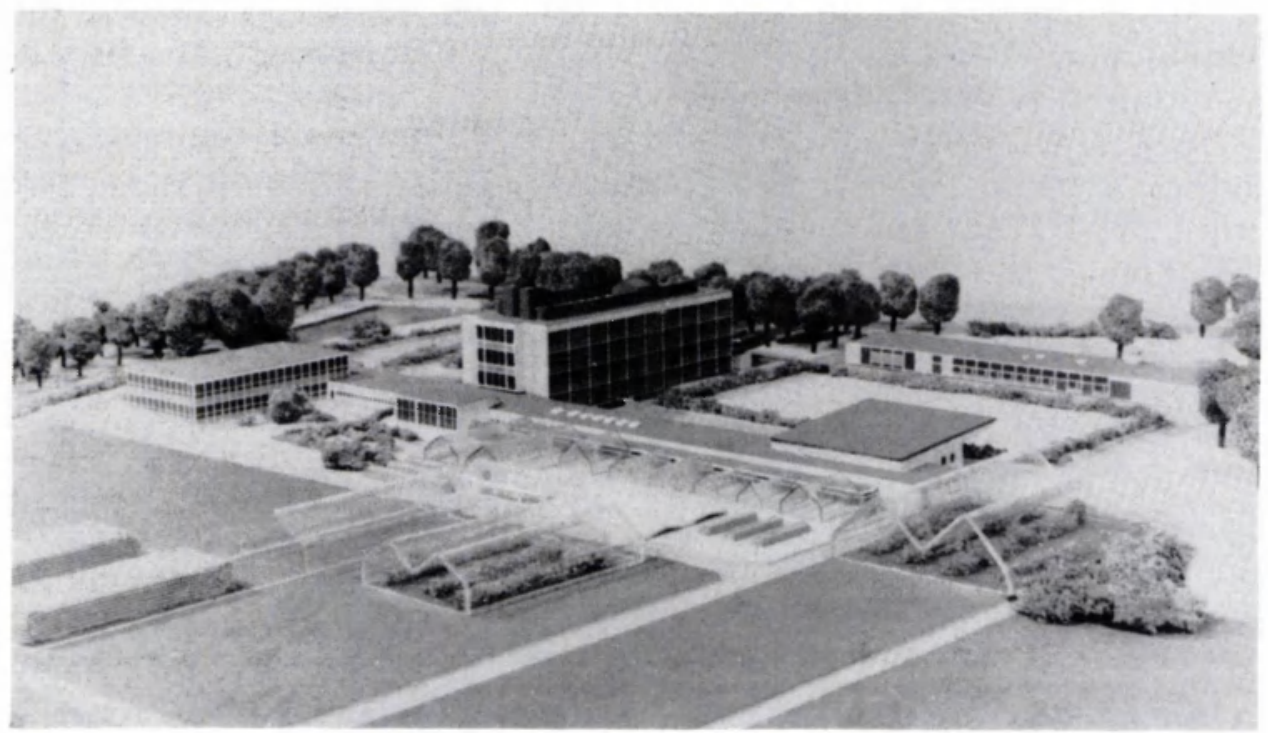

Fig. 11. Scale-model of the new building in Haren. 


\section{Research outlook}

In the past decades, the main objective of soil fertility research was to increase crop production levels and to meet specified crop quality standards. The research on the 'fertility factors' laid the foundation for the system of fertilizer recommendations in the Netherlands, on the basis of soil analysis. This research helped to promote the rational use of fertilizers in the Netherlands, which is now one of the highest in the world, on a per-hectare basis.

Traditionally, soil fertility and fertilization research paid attention to the fraction of the (applied) nutrients that ended up in the crop, thus contributing to higher yields or better quality, but largely ignored the fraction of nutrients not taken up by the crop, that is, stored in the soil or lost from the soil through volatilization, leaching or surface runoff. Hence, soil fertility research focussed on establishing correlative relationships between fertility factors or fertilizer application on the one hand, and crop quality or yield on the other, but did not consider the fate of nutrients not taken up by the crop. From an environmental point of view, however, the latter fraction is the important one, as it determines whether contamination of the environment or undesired effects on the soil biosphere may occur.

Although the emphasis in the research program was on agricultural production, the Institute for Soil Fertility Research has paid attention to environmental issues since the mid-sixties, long before these issues ranked high on the political agenda. For example, the 1970 Annual Report is devoted almost entirely to environmental issues and contains contributions by Dr A. J. de Groot on heavy metals in river sediments, by Ir G. J. Kolenbrander on the eutrophication of surface waters by nitrogen and phosphate, and by $\operatorname{Ir} \mathbf{L}$. C. N. de la Lande Cremer on the expected surpluses of animal manures as a result of intensive animal husbandry.

In 1987 the research task of the Institute for Soil Fertility Research was changed to the effect that the institute had to (1) stengthen its biological research program, (2) redirect its research in the field of fertilization and soil fertility, i.e., pay more attention to the environmental impact of the use of fertilizers, and (3) make more use of simulation modelling and other mathematical techniques for the description of soil-crop ecosystems. This redirection of the research program was part of a reorganization of agricultural research in the Netherlands, as laid down in the 'Development Plan for the Institutes and Experimental Stations of the Ministry of Agriculture and Fisheries, 1987-1990'. The present research program of the Institute for Soil Fertility Research requires a systems approach, making use of quantitativeanalytical methods of research, in order to integrate disciplinary knowledge (physics, chemistry, biology, soil and crop sciences) as well as areas of application: agricultural production, environmental quality, and soil ecology.

The changes in research emphasis at the Institute for Soil Fertility Research in recent years should be viewed against the background of changing economic prospects for agriculture and an increasing public concern about the quality of the environment. The economic prospects for agriculture have changed in the sense that there are now surpluses of many agricultural commodities within the European Community, and it seems that further economic growth has to come from better quality and 


\section{K. HARMSEN}

diversification of products, rather than from higher production levels and more (of the same) products. The public concern about the quality of the environment has led the government to release a number of policy documents, such as the 'National Environmental Policy Plan', which sets environmental aims to be achieved in the next decade(s) and outlines ways of achieving these aims.

In the future research program of the Institute for Soil Fertility Research, mathematical modelling of soil-crop ecosystems will play an important part. The areas of application of the research, that is, agricultural production, environmental quality, and soil ecology, have to be integrated into multidisciplinary research projects. The main objective of the future research program will be to contribute to the development of agricultural systems that are sustainable, safe (for humans and the environment) and economically competitive. The word 'sustainable' is defined here as 'not resulting in any irreversible changes in the (potential) functioning of the soil and not leading to contamination of air or water beyond specified (permitted) levels'. The concept of sustainability will be a leading principle in the future research program. Sustainability is also important on a national scale: decreasing losses of nutrients to the atmosphere and the North Sea, balancing the import (e.g., animal feedstuffs) and the export of nutrients (e.g., meat and dairy products), and recycling nutrients where possible (e.g., animal manures, sewage sludges).

In the past, the Institute for Soil Fertility Research has helped to overcome nutrient deficiencies in Dutch agriculture and to increase production and product quality to their present levels. The challenge now is to maintain a competitive agriculture while preserving the environment.

\section{References}

Harmsen, K., 1990. Institute for Soil Fertility Research 1890-1990. Haren, Netherlands. (In Dutch). Honing, Y. van der \& S. J. Langelaar, 1990. Contribution to animal nutrition in the Netherlands by the Institute of Livestock Feeding and Animal Nutrition Research, IVVO, since 1890. Netherlands Journal of Agricultural Science 38: 399-406. 